\title{
BMJ Open Change in drink purchases in 16 Australian recreation centres following a sugar-sweetened beverage reduction initiative: an observational study
}

\author{
Tara Boelsen-Robinson (D) , ${ }^{1,2}$ Liliana Orellana (1) , ${ }^{3}$ Kathryn Backholer, ${ }^{2}$ \\ Ariana Kurzeme, ${ }^{4}$ Alethea Jerebine (D) , ${ }^{4}$ Beth Gilham (D) , ${ }^{2}$ Alexandra Chung (D) , ${ }^{1,2}$ \\ Anna Peeters (1D ${ }^{2}$
}

To cite: Boelsen-Robinson T, Orellana L, Backholer K, et al. Change in drink purchases in 16 Australian recreation centres following a sugar-sweetened beverage reduction initiative: an observational study. BMJ Open 2020;10:e029492. doi:10.1136/ bmjopen-2019-029492

- Prepublication history and additional material for this paper are available online. To view these files, please visit the journal online (http://dx.doi. org/10.1136/bmjopen-2019029492).

Received 28 January 2019 Revised 17 December 2019 Accepted 03 January 2020

Check for updates

(C) Author(s) (or their employer(s)) 2020. Re-use permitted under CC BY-NC. No commercial re-use. See rights and permissions. Published by BMJ.

${ }^{1}$ School of Public Health and Preventive Medicine, Monash University, Clayton, Victoria, Australia

${ }^{2}$ Global Obesity Centre, Institute for Health Transformation, Deakin University, Geelong, Victoria, Australia

${ }^{3}$ Biostatistics Unit, Faculty of Health, Deakin University, Geelong, Victoria, Australia

${ }^{4}$ YMCA Victoria, Box Hill, Victoria, Australia

Correspondence to Tara Boelsen-Robinson; tara.b@deakin.edu.au

\section{ABSTRACT}

Objective To assess the impact of a sugar-sweetened beverage (SSB) reduction initiative on customer purchasing patterns, including volume sales of healthy and unhealthy packaged drinks and sales value of all packaged drinks, in a major Australian aquatic and recreation provider, YMCA Victoria.

Design Prospective

Setting 16 aquatic and recreation centres in Victoria, Australia.

Interventions The SSB-reduction initiative aimed to remove all SSBs (excluding sports drinks) and increase healthier drink availability over a 1-year period.

Primary and secondary outcome measures Itemised monthly drink sales data were collected for 16 centres, over 4 years ( 2 years preimplementation, 1 year implementation and 1 year postimplementation). Drinks were classified as 'green' (best choice), 'amber' (choose carefully) or 'red' (limit). Interrupted time series analysis was conducted for each centre to determine the impact on volume sales of 'red' and 'green' drinks, and overall sales value. A novel meta-analysis approach was conducted to estimate the mean changes across centres.

Results Following implementation, volume sales of 'red' drinks reduced by $46.2 \%$ across centres $(95 \% \mathrm{Cl}:-53.2 \%$ to $-39.2 \%)$, 'green' drink volume did not change $(0.0 \%$, $95 \% \mathrm{Cl}:-13.3 \%$ to $13.2 \%$ ) and total drink sales value decreased by $24.3 \%$ (95\% Cl: $-32.0 \%$ to $-16.6 \%)$.

Conclusions The reduction of SSBs in health-promoting settings such as recreation centres is a feasible, effective public health policy that is likely to be transferable to other high-income countries with similarly unhealthy beverage offerings. However, complementary strategies should be considered to encourage customers to switch to healthier alternatives, particularly when translating policies to organisations with less flexible income streams.

\section{INTRODUCTION}

Poor nutrition is the leading risk factor for loss of disability-adjusted life years in many high-income countries, for example, the $\mathrm{USA}^{1}$ and Australia, ${ }^{2}$ through diseases such as cardiovascular disease, type 2 diabetes

\section{Strengths and limitations of this study}

- This is the first multicentre study using empirical sales data over a 4-year period.

- Interrupted time series analysis is a robust method for evaluation of natural experiments when its assumptions are satisfied.

- The application of a meta-analysis approach enables estimations of mean relative changes across centres with extremely variable pattern of volume and dollar sales.

- Sales data do not represent actual beverage consumption and this study cannot measure the effect of the intervention on compensatory dietary behaviours in other settings.

- Populations in recreation centres may differ from the general population.

and some cancers. Sugar-sweetened beverages (SSBs) provide little to no nutritional benefit, and have been linked to obesity, ${ }^{3}$ type 2 diabetes ${ }^{4}$ and dental decay. ${ }^{5}$ SSBs have therefore become a popular target for public health initiatives. ${ }^{6-8}$

Settings that already engage in healthpromoting activities or are communitybased, are a natural starting point for shifts to healthier food provision as their goals centre on health and well-being, and in producing public good. ${ }^{9}$ This is particularly pertinent for aquatic and recreation centres (including those that provide aquatic, sports, leisure and/or exercise facilities) which may sell a predominance of unhealthy items in the UK, USA, Canada and Australia. ${ }^{10-13}$ One way for organisations to increase the healthiness of the food environment is by increasing the availability of healthier products, while decreasing the availability of unhealthy ones. ${ }^{14}$ However, there is little evidence on whether such approaches have the intended 
effect on customer purchasing and are feasible for organisations to implement.

Studies conducted within recreation centres have shown that increasing healthy food availability results in greater purchasing of these products. ${ }^{15-17}$ However, these studies are limited by the use of self-reported purchasing data, short duration (<1 year) and/or not accounting for underlying trends when using empirical sales data. Furthermore, no studies examined characteristics associated with outcomes of interest including businessrelated ones. The latter is important given that fear of negative financial outcomes and customer dissatisfaction is a frequently voiced concern by retail storeowners and managers. ${ }^{18-20}$ A further study using interrupted time series analysis to assess the impact of pricing changes to SSBs in UK recreation centres ${ }^{21}$ offers methodological insights that could be applied to the evalution of availability-based policies.

The introduction of an SSB reduction initiative by YMCA Victoria, an Australian community organisation with a large number of recreation centres, provided an opportunity to answer some of these questions. YMCA Victoria manages 65 aquatic and recreation facilities across the state of Victoria (at January 2017). In December 2014, YMCA Victoria announced an SSB reduction initiative, where all SSBs (excluding sports drinks) were to be removed by December 2015, while increasing healthier drink availability. The SSB reduction initiative will be referred to as the 'initiative' here forth. The aim of this study was to assess the impact of this initiative on customer beverage purchasing patterns.

\section{METHODS}

The SSB reduction initiative was the first part of a broader Healthy Food and Beverage Policy within YMCA Victoria. The broader policy aimed to create a healthier nutrition environment for patrons and staff by increasing the availability, and promoting the consumption, of healthy food and beverages, and reducing the availability of less healthy choices. This broader policy was implemented over a 3-year period and is based on Victorian state government 'Healthy Choices: Policy Guidelines for Sport and Recreation Centres' and the corresponding classification guide, which categorises foods and drinks into 'red' (limit intake), 'amber' (choose carefully) or 'green' (best choices).

The focus of this study is on the SSB reduction initiative, which was gradually implemented by centres over

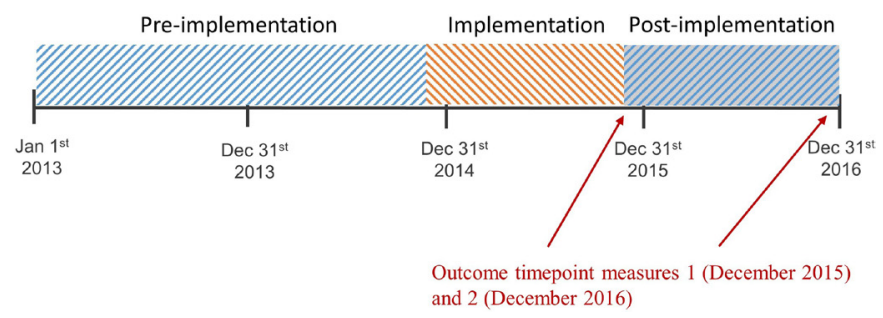

Figure 1 Timeperiod included for analysis. a period of 1 year, from December 2014 to November 2015 (ie, fully implemented by December 2015). Figure 1 demonstrates the periods involved in the SSB reduction initiative.

The initiative aimed to reduce the availability of packaged SSBs classified as 'red'. This was done by focusing on the complete removal of some types of 'red' SSBs, and the reduction of the availability of other types of 'red' SSBs. Across the centres, there was variability in the extent to which the intended removal and reduction of 'red' drinks was achieved. Products intended for complete removal included non-diet carbonated beverages, flavoured water, high kilojoule flavoured milk and fruit drinks with less than $99 \%$ fruit juice. Fruit juice $>250 \mathrm{~mL}$ are also classified as 'red' and were intended for removal. Sports drinks were to be reduced to $<10 \%$ and 'green' options increased to $>70 \%$ of fridge space. Other 'red' drinks such as SSBs that were prepared onsite were not focus of the initiative (eg, milkshakes, see online supplementary table S1) and were still available for purchase.

Complementary strategies included placing the healthier drink alternatives at eye-level, traffic light labels at point of sale, and promotional posters encouraging switching from sugary drinks to healthier alternatives such as water.

\section{DATA COLLECTION Implementation}

All YMCA centres that were the focus of the SSB reduction initiative and satisfied the following eligibility criteria were included in this study:

- Contained a kiosk or café with drinks for sale.

- Café sales data available between December 2013 and December 2016.

- Café sold SSBs in addition to sports drinks during the preimplementation period from December 2013 to November 2014.

- Monthly attendance data (ie, number of visitors to each centre) available from December 2013 to December 2016.

- Centre committed to removing SSBs by December 2015.

- Agreed to participate in the study.

- Underwent no major refurbishments to the centre or café over the study period.

Exclusion criteria were as follows:

- Seasonal pools (only open for part of the year).

- Centres with only vending machines.

YMCA Victoria camps, childcare centres and youth services were also excluded from this study as these settings were not the focus of the SSB reduction initiative.

The initiative was expected to be implemented by December 2015. However, given the challenges of realworld implementation and potential variation in implementation across centres, we conducted several measures of change in drink availability using sales data. We describe the extent of initiative implementation at each 
centre by (1) complete removal of SSBs (excluding sports drinks) by December 2015 (yes/no), (2) removal of carbonated SSBs (the most popular SSBs) by December 2015 (yes/no) and (3) the change in number of packaged 'green', 'amber' and 'red' drink varieties sold one timepoint immediately before (November 2014) and at the timepoint of expected implementation (December 2015). Paired t-tests were used to determine whether the difference between the number of 'red', 'amber' and 'green' drinks available for purchase between these two timepoints was statistically significant. Implementation data are presented first in the results section in order to provide context.

\section{Purchase data}

Each centre provided point-of-purchase, electronic, monthly sales data for all drink items from January 2013 to December 2016 in order to measure type, quantity, volume and dollar sales value of purchases. The preintervention, implementation and postimplementation periods are defined in figure 1. We calculated for each calendar month total volume sales of 'red' and 'green' cold packaged beverages, and 'red' cold packaged and non-packaged beverages based on volume and number of items. Centre attendance data were collected electronically between January 2013 and December 2016 and was used to adjust for centre foot traffic. The collection of this data varied between centres but generally required patrons to scan a membership card.

Artificially sweetened 'diet' carbonated drinks were the main drinks in the 'amber' packaged drink category. A number of centres independently chose to remove, or greatly reduce availability of these products during our study period, while some centres had removed these drinks prior to the study period (total of 10 centres). The remaining centres with artificially sweetened drinks $(n=6)$ had low sales of these products, which were highly variable month to month, preventing the production of meaningful results. This was determined by the sales data. Therefore, 'amber' sales data were not analysed separately, however was considered in analysis of total sales.

\section{Data coding}

All drink items were classified by an Accredited Practising Dietitian (APD) that was part of the research team, using the Healthy Choices classification guide. ${ }^{22}$ Classification was crosschecked with in-depth menu assessments conducted by the organisation. Ten percent of items were cross-coded by another APD, with any discrepancies resolved through discussion. Information on sugar content (grams) was collected from nutrition information on packaged drink labels. Inter-rater reliability for drink categorisation was $88 \%$. The miscategorised drinks tended to be those that were not commonly available, and therefore unfamiliar to the coders, as well as having low numbers of items sales. In total, the miscategorised drinks accounted for $0.49 \%$ of total sales over the 4 -year period of analysis.
Using information provided by YMCA head office, centres were categorised according to food preparation facilities (café-full hot and cold food preparation facilities; canteens-some preprepared food facilities; kioskonly prepackaged food and drinks available), recreation facilities (presence of pool (yes/no), stadium (yes/no) and health club (yes/no)), income of the café, kiosk or canteen (high, medium and low), initiative implementation (targeted SSBs removed by December 2015 (yes/ no)) and whether diet-carbonated beverages were available during the postimplementation period (yes/no). Centres were additionally stratified by socioeconomic position (SEP), based on the geographic location using the Socio-Economic Index For Areas (SEIFA) (highSEIFA percentile $>65$, medium-SEIFA percentile 34-65 and low-SEIFA percentile <34). SEIFA is an Australianspecific area measure of relative disadvantage based on national census data. ${ }^{23}$

\section{Statistical analysis}

Given the focus of the initiative was packaged drinks; the primary outcomes of this analysis were volume sales of cold packaged 'red' drinks, cold packaged 'green' drinks, sugar content of all cold packaged drinks purchased ('red', amber' and 'green') and dollar sale value of all cold packaged drinks. These outcomes captured: (1) impact on initiative-targeted drinks (volume of 'red' drinks); (2) changes in behaviour in substitution to other beverages (volume of 'green' drinks); (3) impact on excess sugar intake and (4) impact on cold packaged drink revenue. Secondary outcomes were 'red' volume sales of cold drinks (packaged and non-packaged), dollar value of cold drinks and dollar value of all drinks (ie, cold and hot drinks). Dollar sales of drinks is used as a proxy for profitability and to assess the potential financial impact of the initiative. Total dollar value is a commonly used measure of business outcomes in healthy food retail evaluations. ${ }^{24}$

All analyses were conducted under an intention to treat approach, that is, we assessed the impact of the initiative regardless of the extent of initiative implementation. This approach aimed to provide insight on the effect of the head office directing the introduction of such an initiative within sport and recreation settings. The effect of the initiative was estimated at two timepoints: (a) immediately following the expected implementation date (December 2015), and (b) 1 year later to measure the sustained impact of the initiative (December 2016). Given that the SSB reduction initiative was introduced from head office at the same time in the entire organisation, there was no opportunity to collect data in 'control centres'.

\section{Analytical approach and rationale}

For each outcome measure, the following strategy was used to estimate the initiative impact at each one of the two selected time points. First, for each centre, we fitted a segmented regression with three periods (preimplementation, implementation and postimplementation). We decided to fit individual interrupted time series 
analysis (ITSA) models to overcome the large variability in volume and dollar sales data observed across centres and the different seasonal patterns depending on the type of centre (see online supplementary figure S1 for examples of raw and fitted data in two centres, and online supplementary figure S2 for examples of raw data for all 16 centres); and to account for the fact that initiative implementation was likely to differ across centres. Then, we calculated at each time point (December 2015 and December 2016) the relative difference (see definition below) between the expected outcome under the ITSA model and the counterfactual outcome had the initiative not been implemented. Therefore, the initiative effect for each centre was summarised in an outcome metric which was comparable across centres. Finally, we summarised the initiative effect at each time point using a randomeffect meta-analysis approach.

Interrupted time series analysis

We proposed the model displayed in Eq. 1, where $t$ indicates time in months; $S_{1}, S_{2}$ and $S_{3}$ are indicators of autumn (March-May), winter (June-August) and spring (September-November) respectively; $A_{\mathrm{t}}$ represents attendance at month $t$ (number of visits to the centre) and $I(B)$ is an indicator function taking the value 1 if condition $B$ is true and 0 otherwise,

$$
\begin{aligned}
E\left(Y \mid t, S_{1, t}, S_{2, t}, S_{3, t}, A_{t}\right) \quad & =\beta_{0}+\beta_{1} S_{1, t}+\beta_{2} S_{2, t}+\beta_{3} S_{3, t}+\beta_{4} A_{t}+ \\
& \beta_{5} t+I(t \geq 24)\left[\beta_{6}+\beta_{7}(t-24)\right] \\
& +I(t \geq 36)\left[\beta_{8}+\beta_{9}(t-36)\right]
\end{aligned}
$$

The model included three periods: preimplementation (1 January 2013 to 30 November 2014; months 1-23), implementation (1 December 2014 to 30 November 2015; months 24-35) and postimplementation (1 December 2015 to 31 December 2016; months 36-48). The implementation period was included to account for the fact that centres were given 1 year to fully implement the initiative. Season and attendance were included to account for fluctuations in sales due to seasonality and special sport events, respectively. This model assumes that the underlying relation between outcome and time, conditional on season and attendance, is linear while allowing for a shift at each breakpoint $\left(\beta_{6}, \beta_{8}\right)$ and for different slopes at different periods $\left(\beta_{5}, \beta_{5}+\beta_{7}, \beta_{5}+\beta_{7}+\beta_{9}\right)$. The model also assumes that the effects of attendance $\left(\beta_{4}\right)$ and seasonality $\left(\beta_{1}, \beta_{2}, \beta_{3}\right)$ are constant across periods. Under the usual ITSA assumptions, described below, the model provides for any given time $t$ estimates of the expected outcome under intervention $\left(\mu_{f, t}\right)$ and the expected counterfactual outcome had the intervention not occurred $\left(\mu_{c, t}\right)$. Our estimation goal was the relative change in the expected outcome, that is, $\Delta_{t}=\frac{\left(\mu_{f, t}-\mu_{f, t}\right)}{\mu_{c f, t}}$, at the two time points of interest (December 2015 and December 2016).

The ITSA approach relies on the usual assumptions of linear regression, mainly that the model is correctly specified. The key untestable assumption underlying the estimation of counterfactual outcomes is that the preintervention trend would have continued unchanged into the implementation and postimplementation periods had the initiative not been implemented. That is, there are no factors that have systematically affected the trend except for those that have been accounted for in the model. ${ }^{25}$

The model was fitted assuming an autoregressive correlation lag 3, using the Newey-West estimation method. The counterfactual outcomes at the time points of interest were estimated according to Eq. 2 where the 'hat' indicates estimated parameters under model (Eq. $1)$. The delta method was used to calculate approximated 95\% CI for the estimation target $\Delta_{t} \cdot{ }^{26}$

$$
\hat{\mu_{c f, t}}=\hat{\beta}_{0}+\hat{\beta}_{1} S_{1, t}+\hat{\beta}_{2} S_{2, t}+\hat{\beta}_{3} S_{3, t}+\hat{\beta}_{4} A_{4}+\hat{\beta}_{5} t
$$

\section{Sugar purchase calculation}

Estimates of change in sugar purchased were derived from the analysis of 'sugar content of all cold packaged drinks'. We calculated the absolute difference for each month, with a significant difference, following initiative implementation (December 2014 to December 2016). These monthly amounts were for all months and all centres to obtain an overall reduction in sugar purchased from the centres as a result of the initiative.

\section{Meta-analysis}

Individual centre estimates were combined using a metaanalysis approach in order to obtain a summary of initiative effect, explore the consistency of the effect size across individual centres, and identify whether outcomes varied when stratified by centre characteristics. A random-effect meta-analysis model was fitted, with equal weighting for centres, to reflect the fact that each centre contributed with the same amount of information independently of sales volume. We proposed a random-effect model because we considered that the initiative effect on the sale outcomes could vary across centres both by chance and also due to factors such as uptake of the initiative, type of centre (eg, presence of a swimming pool, or offering at cafe) or customer's characteristics (eg, age and socioeconomic level). We conducted stratified meta-analysis to explore heterogeneity of effects across centre characteristics. The analysis was stratified by food preparation facilities (café, canteen and kiosk), income of the café (classified as high, medium and low), SEP of the centre area (high, medium and low), recreation facilities (pool, stadium and health club), initiative implementation ('red' carbonated beverage available at end of period) and whether diet-carbonated beverages were available during the postimplementation period. We report the estimates and CIs for each stratum.

Assumptions underlying meta-analysis were clearly satisfied. ${ }^{27}$ The YMCA centres corresponded to the 'studies' contributing to the meta-analysis. The effect measure was estimated following the same approach for the different centres, that is, effect size measures are comparable and of the same quality. The target population to which the 
summary estimate of effect applies is also clearly defined, that is, YMCA centres in Victoria applying the SSB reduction initiative. All centres satisfying the eligibility criteria were included in the study.

An additional meta-analysis was conducted to assess the robustness of our results using yearly drink revenue at December 2015, as the centre weight.

\section{Other considerations}

To maintain anonymity, centres are referred to by Centre 1-16. One centre (identified as 11) implemented the initiative immediately and had zero sales of 'red' cold packaged drinks during and following the initiative implementation period (after November 2014). Due to nonvariability of the observed outcomes, the model could not be estimated, and this centre was excluded from the analysis of 'red' cold packaged and 'red' cold volume sales but is included in all other analyses.

Of 16 centres included in the analyses, three centres (3, 4 and 9) displayed low sales of beverages and attendance over December and January each year. Centre9 was closed during 4 weeks over Christmas, and centres 3 and 4 were small centres with stadiums and no pools and therefore very low activity. December and January data were combined for these centres and the model fitted using an ' 11 month year'; that is, the indicators functions in Eq. (1) were set to $I(t \geq 23)$ and $I(t \geq 34)$. Three centres (identified as 8,9 and 13) had low or zero total sales or missing attendance data at seemingly random months. We contacted the centre managers to explore the reasons for this, which were all due to the centre or the café being closed or undergoing refurbishment for less than 1 month. These data points were imputed carrying forward sales and attendance values from the previous month. Two centres had five imputations each, and one centre had one imputation. All analyses were carried out using Stata V.14.

We considered that differences in the increase of the price of drinks sold over time may affect the assumptions under ITSA. The raw data demonstrate small and consistent increases in price per unit over time across all centres (less than a $4 \%$ increase annually).

\section{Patient and public involvement}

Patients and the public were not involved in this study.

\section{RESULTS}

A total of 16 centres were included for analysis (see figure 2 for selection of included centres). The distribution of 'included centre characteristics' is presented in online supplementary Table S2. The average monthly volume of green drinks across the 16 centres ranged between $39 \mathrm{~L}$ and $537 \mathrm{~L}$ with a median of $169 \mathrm{~L}$ indicating the heterogeneity of the beverage sales within centres included in this study.

\section{Initiative implementation}

Thirteen of the 16 centres had a reduced number of 'red' cold packaged drinks for sale by December 2015, however

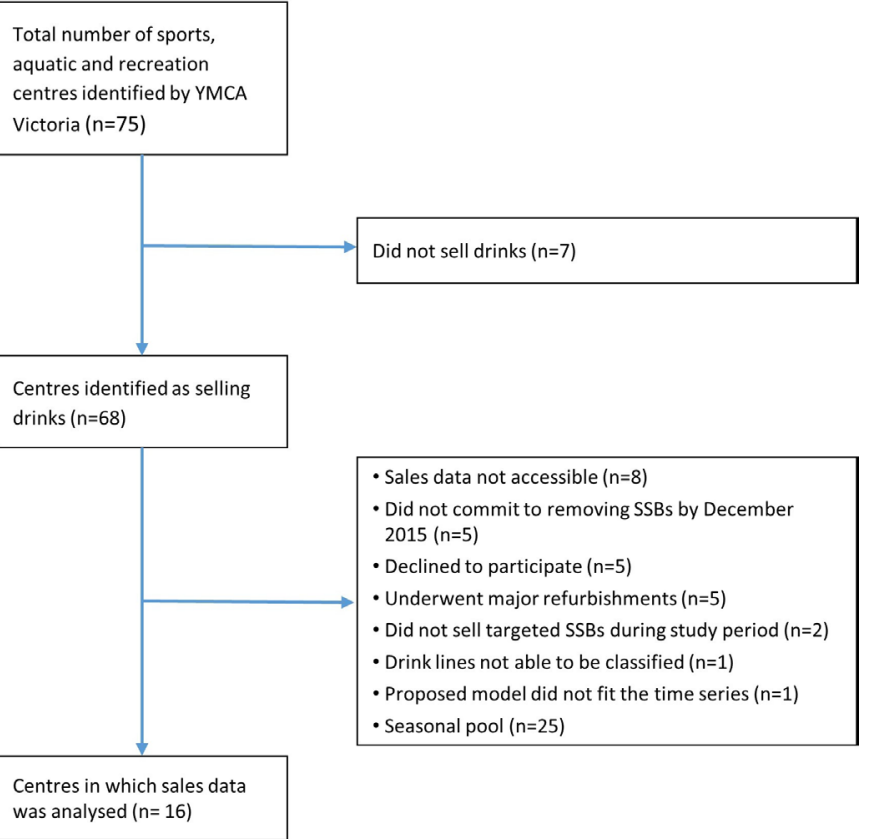

Figure 2 Centre selection.

no centres had fully implemented the initiative (ie, did not sell a non-sports drink 'red' cold packaged drink at this time point), see online supplementary table S3. Eight centres had removed carbonated SSBs. By December 2015, there were on average 5.9 (95\% CI: 3.4 to 8.5) fewer varieties of 'red' cold packaged drinks available for sale per centre compared with November 2014 (13.8, 95\% CI: 10.6 to 17.0$)$; 'green' drink varieties increased by 1.6 (95\% CI: 0.7 to 2.6 ), from 3.7 (95\% CI: 2.3 to 5.1 ) while availability of different kinds of 'amber' beverages did not change $(-0.2,95 \%$ CI: -1.1 to 1.5$)$ from 2.6 (95\% CI: 1.2 to 3.9). The mean number of all available packaged drink varieties significantly decreased by 1.4 (95\% CI: -2.7 to $-0.0)$.

Volume sales of 'red' cold packaged drinks as a proportion of all cold packaged sales decreased from an average of $48 \%$ (range: $32 \%-73 \%$ ) in the preimplementation period to an average of $27 \%$ (range: $9 \%-51 \%$ ) in the implementation period $(\mathrm{p}<0.05)$. The proportion of cold packaged volume sales that constituted 'green' drinks increased from $44 \%$ (range: $23 \%-62 \%$ ) to $62 \%$ (range: $34 \%-84 \%$ ).

\section{Purchasing patterns}

Following initiative implementation, across the 15 centres included in this ITSA analysis, volume sales of the targeted drinks ('red' cold packaged drinks) decreased by $46.2 \%$ (95\% CI: $-53.2 \%$ to $-39.2 \%$ ) at December 2015, compared with expected sales had the initiative not been implemented (figure 3). For a summary of results of primary and secondary analysis at December 2015, see online supplementary table S4. The magnitude of the reduction was maintained at December 2016 (online supplementary table S4). The reduction in volume of 'red' cold packaged drinks equates to 10999 fewer litres 


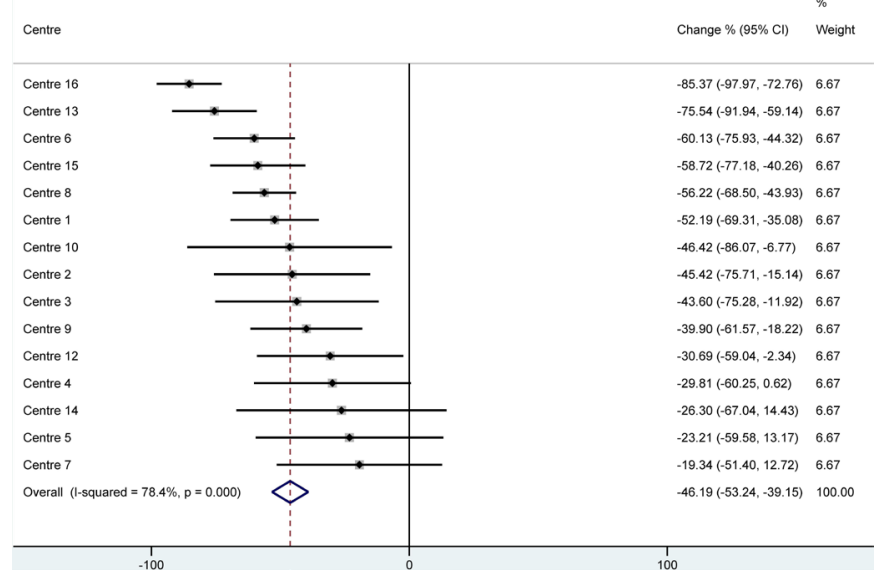

Figure 3 Change in volume sales of red packaged drinks December 2015.

of SSBs sold from December 2014 to November 2016, across the 15 centres included in this analysis.

Summary estimates stratified by key centre characteristics showed observable differences in reduction between centres that had 'red' carbonated soft drinks available $(-35.2 \%, 95 \%$ CI: $-46.7 \%$ to $-23.7 \%)$ compared with centres where these beverages had been fully removed $(-58.8 \%, 95 \%$ CI: $-66.2 \%$ to $-51.4 \%)$. Stratification by other variables did not show observable differences (online supplementary table S5).

'Green' cold packaged beverage volume sales neither changed at December 2015 (0.0\%, 95\% CI: $-13.3 \%$ to $13.2 \%$ ), see figure 4, nor at December 2016 (online supplementary table S4). Stratification by variables of interest revealed differences, although non-significant, in 'green' drink volume sales between centres that had removed 'red' soft drinks $(9.9 \%, 95 \%$ CI: $-6.8 \%$ to $26.5 \%)$ and those that had not $(-9.9 \%, 95 \%$ CI: $-30.5 \%$ to $10.7 \%)$ and between centres with pools $(13.7 \%, 95 \% \mathrm{CI}:-2.5 \%$ to $30.0 \%)$ and without pools $(-17.7 \%, 95 \%$ CI: $-39.6 \%$

Figure 4: Change in volume sales of green packaged drinks December 2015

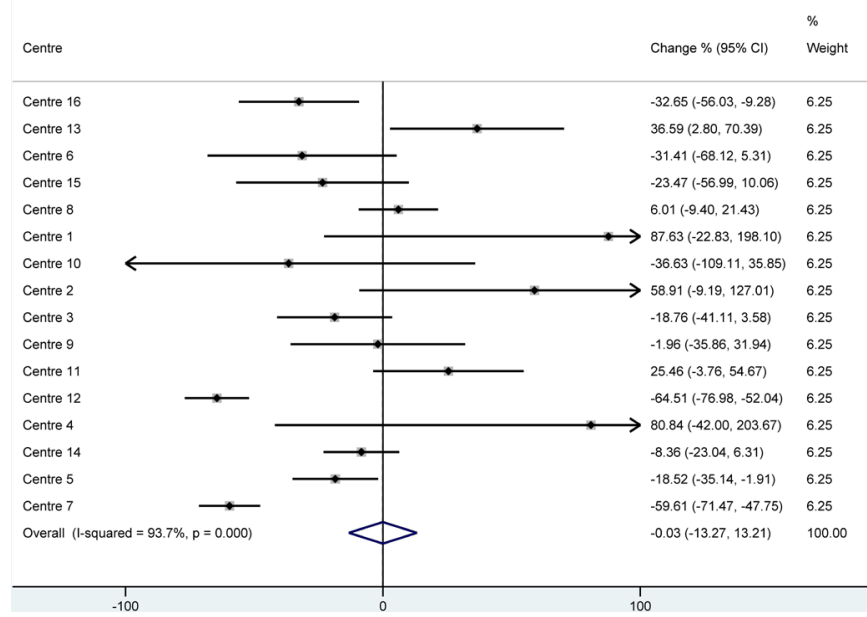

Figure 4 Change in volume sales of green packaged drinks December 2015.

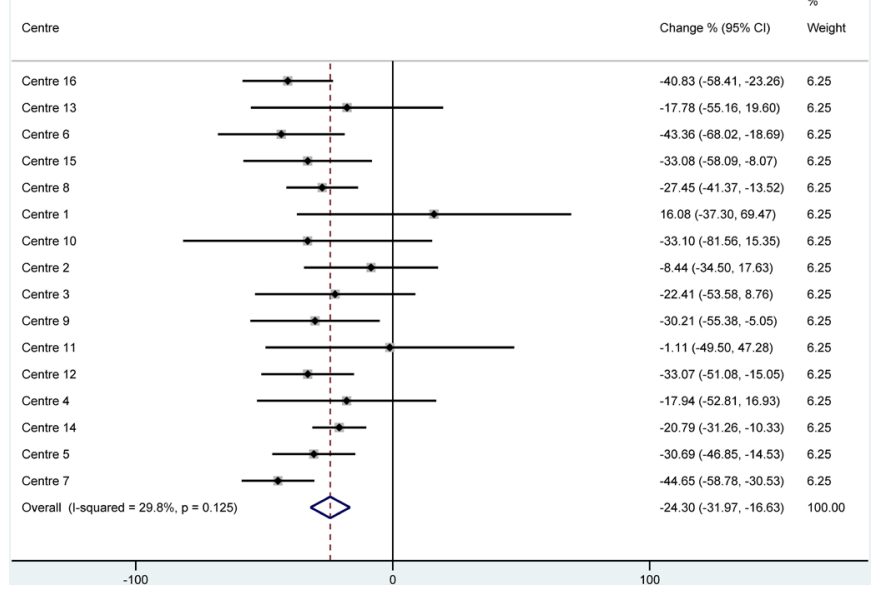

Figure 5 Change in dollar sales of packaged drinks December 2015.

to $4.1 \%)$. Other stratifications did not reveal observable differences (online supplementary table S5).

The initiative resulted in a significant reduction in the purchase of sugar in packaged drinks across the 16 centres at December 2015 (-34.5\%, 95\% CI: $-44.4 \%$ to $-24.5 \%)$, which was attenuated at December 2016 (online supplementary table S4). During the 2-year time period from December 2014 to November 2016, an estimated 577 fewer kilograms of sugar were sold from packaged drinks across the 16 centres.

Volume of 'red' cold drinks (packaged and nonpackaged drinks) sales significantly decreased by $42.3 \%$ (95\% CI: $-59.7 \%$ to $-24.9 \%$ ) at December 2015 , which was maintained 1 year later (online supplementary table S4).

\section{Impact on sales value of packaged drinks}

Total cold packaged beverage sales value was reduced by $24.3 \%$ (95\% CI: $-32.0 \%$ to $-16.6 \%$ ) at December 2015 compared with the predicted sales had the initiative not been implemented (figure 5). This reduction was ameliorated by December $2016(-15.4 \%, 95 \%$ CI: $-35.8 \%$ to $4.9 \%)$.

Within all cold beverage sales (packaged and nonpackaged), there was a $25.2 \%$ (95\% CI: $-32.2 \%$ to $-18.1 \%$ ) decrease at December 2015, which was similar at December 2016 (online supplementary table S4).

Total drinks sales value (all hot and cold drinks, packaged and non-packaged) decreased by $18.5 \%$ (95\% CI: $-25.6 \%$ to $-11.4 \%$ ) at December 2015, compared with if the initiative had not been implemented. This decrease was ameliorated at December 2016, 1 year after initiative implementation $(-12.3 \%, 95 \%$ CI: $-29.0 \%$ to $4.5 \%$; online supplementary table $\mathrm{S} 4$ ).

Stratification by variables of interest did not reveal differences in cold packaged drink sales (see online supplementary table S5), cold drink sales (results not shown) or total drink sales (results not shown). Changing the weight in the meta-analysis approach did not alter the 
outcomes of any of the primary or secondary outcomes (results presented in online supplementary table S4).

\section{DISCUSSION}

This is the first evaluation of an organisational-wide initiative to reduce SSB availability within recreation centres, combining interrupted time series analysis of monthly sales data with meta-analysis. We found that after 1 year of implementation sales of the unhealthiest 'red' drinks substantially decreased, sales of healthiest 'green' drink options did not change, and sales of all packaged cold drinks and sales of all drinks decreased. These changes were generally sustained 1 year postimplementation. The decline in total sales was somewhat ameliorated at 1 year, however such evidence is inconclusive due to wide CIs.

A major strength of this study is the use of objective beverage sales data that is not limited by recall and social desirability bias. ${ }^{28}$ A further strength is the large number of centres included. The length of the time series data (36 time points over 3 years) allowed adjustment for underlying declining trends in SSB consumption in Australia, ${ }^{29}$ seasonal purchasing patterns and centre attendance. ITSA is a method for the evaluation of natural experiments ${ }^{30}$ under a set of assumptions that has previously been used in similar research contexts. ${ }^{32}$ Finally, the use of a meta-analysis to independently combine effect estimates by centre avoids modelling all centres in a common model, avoids using the time series aggregate measure of sales across centres and allows the exploration of heterogeneity in the change in sales across centres.

A weakness of this study is the inability of sales data to represent actual beverage consumption and the lack of understanding of intervention effects on compensatory dietary behaviour in other settings. Previous studies evaluating compensatory behaviour following removal of SSBs in schools have found no increased consumption outside of school, ${ }^{33}$ or increased consumption that was of a smaller magnitude than the decrease in school-based consumption. ${ }^{34}$ While school settings are not completely analogous to sport and recreation settings, there is clear potential for availability changes in one settings to affect total consumption. Total sales is an imperfect proxy for profitability and financial viability; however, the reporting of business outcomes is important when considering the application of policies to commercial settings. ${ }^{24}$ Sales data were used to measure the degree of implementation of the initiative. Although it does not measure the proportion of fridge shelf-space occupied by 'red' drinks (one of the interventions intent), it does capture when 'red' drinks targeted for removal are no longer sold. A further limitation is the unavailability of 'control' centres; as a consequence, the estimation of the counterfactual outcomes relays on the strong assumption that the preimplementation model is valid into the future, that is, there are no factors besides those included in the model that will affect the outcome and that the "effect" of these factors is constant across periods. ${ }^{35}$ Further, the generalisability of findings may be limited to similar recreation settings with comparable populations. However, sport settings in countries such as the UK, Canada and the USA seem to reflect similarly unhealthy beverage offerings; $;^{11} 13$ there is likely to be comparable, transferable public health benefit from implementing SSB-reduction policies within these contexts. Wide CIs for some outcomes at December 2016 (ie, 'green' drink volume) limit the interpretability of the results. Finally, 'substitution' of drinks is based on estimates of change obtained under univariate time series analysis for two outcomes that are actually correlated, 'red' and 'green' packaged drinks.

Our findings of a decline in unhealthy drink purchases are consistent with existing literature using before-andafter analysis of policies aimed at removing the unhealthy and/or increasing healthier food and drink options. An Australian study within an outdoor pool setting ${ }^{16}$ reported a $45 \%$ reduction in kilojoules sold per attendee, and a $72 \%$ reduction in saturated fat, while a Canadian study in a similar setting reported a decrease of unhealthy items sales from $92 \%$ to $77 \%$. $^{17}$

Our findings that healthiest drink purchases ('green') did not change is inconsistent with the literature. Olstad et $a l^{17}$ found that following an increase in healthy food and beverage provision over a 40-day period in a Canadian outdoor pool, there was a significant increase in the proportion of sales of healthier options compared with the preintervention period. Wolfenden et $a l^{15}$ found that in sports clubs that received an intervention aimed at increasing the availability and promotion of non-sugar sweetened beverages over 2.5 winter sporting seasons, there was a significantly increased self-reported purchasing of non-SSBs by a factor of 1.56, compared with control clubs. These studies are also in contrast with our finding that overall sales of cold packaged drinks decreased postintervention. ${ }^{15-17}$

These contrasting findings may be due to several factors. First, customers may have switched to the free, palatable drinking water available from centre water fountains, accounting for the lack of change in 'green' drinks, and related decline in total sales. Second, nine of 16 centres in our study did not have diet-carbonated drink alternatives and the limited number of centres that did have 'amber' drinks precluded a subanalysis to explore whether some compensatory behaviours occurred (ie, switching from 'red' to 'amber' drinks). The unplanned parallel removal of both diet-carbonated beverages and SSBs in a number of centres highlights the complexity of implementing and evaluating real-world policies. The large size and methodological robustness of our study differ from the existing literature; two studies were conducted in one swimming centre each, ${ }^{1617}$ while the third used self-reported sales. ${ }^{15}$ There is also likely to be publication bias towards results that do not demonstrate a decline in business outcomes with the introduction of public health policies. This highlights the importance of our study, which shows that some settings may experience a decline in total sales. Finally, the aforementioned studies examined the impact of 
food and beverage availability policies, whereas our study purely examined an SSB reduction initiative. Our findings of a lack of increase in 'green' sales is similar to a study examining the impact of a $20 \%$ price increase on SSBs in seven UK recreation centres where patrons switched from the unhealthier SSBs to artificially sweetened SSBs, rather than to water. ${ }^{21}$

While promotional material was provided to centres to support the initiative, analysis was not undertaken to evaluate the extent to which the materials were used; future research should investigate whether targeted complementary strategies, such as pricing, promotion and labelling, have additional impact to increase sales of healthy and reduce sales of unhealthy beverages.

The movement of consumer demand away from sugarladen drinks to healthier alternatives in high-income countries is of great interest to beverage manufacturers, ${ }^{36}$ and is driving innovation of healthier low and no-calorie alternatives, ${ }^{37}$ providing a wider range of acceptable alternatives to SSBs. The adoption of this initiative by the state's largest recreation provider (with 17 million visits per annum) sends a strong signal to manufacturers that community and health-promoting organisations are seeking healthier alternatives. Furthermore, Melbourne, Victoria has safe and palatable drinking water, and all centres had at least one accessible, free, water fountain. Settings and locations with less palatable and accessible water may see a more observable shift towards bottled water sales after SSB removal within their facilities.

Replacing just one can of SSB a day with water can significantly improve health and has been modelled to result in a modest but significant reduction in obesity rates. ${ }^{38}$ Extrapolation of the response to this policy to all sports and recreation facilities across Australia would lead to over 3.5 million fewer cans of SSB purchased per year. Future research is needed to analyse the impact of the purchasing reductions of healthy food retail interventions such as this on overall diet.

Customers may seek to purchase unhealthy drinks elsewhere as a result of low availability within sports centres. The evidence on the degree to which they are likely to do so is limited and mixed. ${ }^{33} 34{ }^{39}$ Future research is needed to identify the extent of such substitution and strategies to reduce it. Government policy to reduce SSB availability across more settings is one means of addressing compensatory behaviours, and creating a level-playing field where retailers face fewer financial disincentives for taking action on public health nutrition.

Health-promoting and community-based organisations are ideal settings in which to initiate healthy food and beverage policies and interventions that may be viewed as potentially risky by the wider food retailer or food service community. They are already engaged in healthpromotion activities and/or are expected to produce public good by the wider community, and the financial risk is less as food retail is generally not the major income source. Studies such as this demonstrating that healthy food and beverage interventions can be feasible and effective to implement, while only moderately impacting overall sales within these organisations can aid a shift to healthy food retail more broadly by lowering the perceived risk.

\section{CONCLUSION}

In this study, we show clear public health benefits of implementing an SSB removal initiative in recreation settings, although with moderate financial impact. Creating healthier nutrition environments through increased healthy drink (and potentially food) availability within the community, and especially in settings that children frequent, is an essential step in improving population-wide diets and turning the tide in nutritionrelated, chronic disease burden.

Twitter Tara Boelsen-Robinson @taraboelsenr, Kathryn Backholer @KBackholer and Anna Peeters @AnnaPeetersAus

Acknowledgements We would like to thank Stephen Bendle, Stella Cifone and the YMCA centre managers and staff.

Contributors AP, LO, TBR, KB and AC designed the study. AK, AJ and TBR coordinated data collection. $\mathrm{AC}$ and $\mathrm{BG}$ conducted data coding and data organisation. TBR, LO and KB conducted data analysis. TBR, AP, KB and LO interpreted the data. All authors contributed to the writing of the manuscript.

Funding This study was funded in part by VicHealth. TBR is supported by an Australian Government Research Training Program Scholarship, a National Health and Medical Research Council Centre for Research Excellence grant (APP1152968) and a grant from The Australian Prevention Partnership Centre. LO is supported by Deakin University. KB is supported by a National Heart Foundation Future Leader Fellowship (102047). AK is supported by YMCA Victoria. $\mathrm{AJ}$ is supported by YMCA Victoria. BG is supported by research funding from the Victorian Health Promotion Foundation (VicHealth). AC is supported by an Australian Government Research Training Program Scholarship. AP is supported by a National Health and Medical Research Council fellowship (GNT1045456) and Deakin University.

Competing interests Professor Peeters has received funding from Melton and Wyndham city councils to conduct evaluations of healthy food policies. Ms Kurzeme and Ms Jerebine are employed by YMCA Victoria. Dr Boelsen-Robinson, Associate Professor Orellana, Dr Backholer, Ms Gilham and Mrs Chung declare no competing financial interests.

Patient consent for publication Not required.

Ethics approval This study has been approved by the Monash University Human Research Ethics Committee (CF16/691-2016000340) and conforms to principles embodied in the Declaration of Helsinki.

Provenance and peer review Not commissioned; externally peer reviewed.

Data availability statement No data are available. Data are commercially sensitive and therefore cannot be provided.

Open access This is an open access article distributed in accordance with the Creative Commons Attribution Non Commercial (CC BY-NC 4.0) license, which permits others to distribute, remix, adapt, build upon this work noncommercially, and license their derivative works on different terms, provided the original work is properly cited, appropriate credit is given, any changes made indicated, and the use is non-commercial. See: http://creativecommons.org/ licenses/by-nc/4.0/.

\section{ORCID iDs}

Tara Boelsen-Robinson http://orcid.org/0000-0003-1671-3091

Liliana Orellana http://orcid.org/0000-0003-3736-4337

Alethea Jerebine http://orcid.org/0000-0002-1396-244X

Beth Gilham http://orcid.org/0000-0002-0689-2850

Alexandra Chung http://orcid.org/0000-0001-7121-9534

Anna Peeters http://orcid.org/0000-0003-4340-9132 


\section{REFERENCES}

1 U. S. Burden of Disease Collaborators. Burden of disease Collaborators. The state of US health, 1990-2010: burden of diseases, injuries, and risk factors. JAMA 2013;310:591-606.

2 Institute for Health Metrics and Evaluation. GBD profile. Australia: Insitute for Health Metrics and Evaluation, 2011.

3 Malik VS, Schulze MB, Hu FB. Intake of sugar-sweetened beverages and weight gain: a systematic review. Am J Clin Nutr 2006;84:274-88.

4 Malik VS, Popkin BM, Bray GA, et al. Sugar-sweetened beverages and risk of metabolic syndrome and type 2 diabetes: a metaanalysis. Diabetes Care 2010;33:2477-83.

5 Bleich SN, Vercammen KA. The negative impact of sugar-sweetened beverages on children's health: an update of the literature. BMC Obes 2018;5:6

6 Backholer K, Spencer E, Gearon E, et al. The association between socio-economic position and diet quality in Australian adults. Public Health Nutr 2016;19:477-85.

7 Morley B, Niven P, Dixon $\mathrm{H}$, et al. Population-based evaluation of the 'LiveLighter' healthy weight and lifestyle mass media campaign. Health Educ Res 2016;31:121-35.

8 Terry-McElrath YM, Chriqui JF, O'Malley PM, et al. Regular soda policies, school availability, and high school student consumption. Am J Prev Med 2015;48:436-44.

9 Boelsen-Robinson T, Backholer K, Corben K, et al. The effect of a change to healthy vending in a major Australian health service on sales of healthy and unhealthy food and beverages. Appetite 2017;114:73-81.

10 Naylor P-J, Bridgewater L, Purcell M, et al. Publically funded recreation facilities: obesogenic environments for children and families? Int J Environ Res Public Health 2010;7:2208-21.

11 Nowak M, Jeanes Y, Reeves S. The food environment in leisure centres and health clubs: how appropriate is it for children? Nutrition Food Sci 2012;42:307-14.

12 Kelly B, Chapman K, King L, et al. Double standards for community sports: promoting active lifestyles but unhealthy diets. Health Promotion Journal of Australia 2008;19:226-8.

13 Thomas HM, Irwin JD. Food choices in recreation facilities: operators' and patrons' perspectives. Can J Diet Pract Res 2010;71:180-5

14 Glanz K, Sallis JF, Saelens BE, et al. Healthy nutrition environments: concepts and measures. Am J Health Promot 2005;19:330-3.

15 Wolfenden L, Kingsland M, Rowland BC, et al. Improving availability, promotion and purchase of fruit and vegetable and non sugar-sweetened drink products at community sporting clubs: a randomised trial. Int J Behav Nutr Phys Act 2015;12:35.

16 McGrath G, Tinney M. Case study: healthy choices at Lara pool. Geelong: State Government of Victoria, 2014.

17 Olstad DL, Goonewardene LA, McCargar LJ, et al. If we offer it, will children buy it? sales of healthy foods mirrored their availability in a community sport, commercial setting in Alberta, Canada. Child Obes 2015;11:156-64.

18 Song H-J, Gittelsohn J, Kim M, et al. Korean American Storeowners' Perceived Barriers and Motivators for Implementing a Corner StoreBased Program. Health Promot Pract 2011;12:472-82.

19 Gardiner B, Blake M, Harris R, et al. Can small stores have a big impact? A qualitative evaluation of a store fruit and vegetable initiative. Health Promot J Austr 2013;24:192-8.
20 Blake MR, Peeters A, Lancsar E, et al. Retailer-led sugarsweetened beverage price increase reduces purchases in a hospital convenience store in Melbourne, Australia: a mixed methods evaluation. J Acad Nutr Diet 2018:118:1027-36.

21 Breeze P, Womack R, Pryce R, et al. The impact of a local sugar sweetened beverage health promotion and price increase on sales in public leisure centre facilities. PLoS One 2018;13:e0194637.

22 Department of Health. Healthy choices: food and drink classification guide. Melbourne: State of Victoria, 2014.

23 Australian Bureau of Statistics. Causes of death, Australia, 2017. Canberra, Australia: Australian Government, 2017. http://www.abs. gov.au/ausstats/abs@.nsf/Lookup/by\%20Subject/3303.0 2017 Main\%20Features Australia's\%20leading\%20causes\%20of\%20 death, \%202017 2

24 Blake MR, Backholer K, Lancsar E, et al. Investigating business outcomes of healthy food retail strategies: a systematic scoping review. Obes Rev 2019;20:315-6.

25 Linden A. Conducting interrupted time-series analysis for single- and multiple-group comparisons. Stata J 2015;15:480-500.

26 Zhang F, Wagner AK, Soumerai SB, et al. Methods for estimating confidence intervals in interrupted time series analyses of health interventions. J Clin Epidemiol 2009;62:143-8.

27 O'Connor AM, Sargeant JM. Meta-Analyses including data from observational studies. Prev Vet Med 2014;113:313-22.

28 Beaton GH, Burema J, Ritenbaugh C. Errors in the interpretation of dietary assessments. Am J Clin Nutr 1997;65:1100S-7.

29 Australian Bureau of Statistics. Children's risk factors. Canberra: Commonwealth of Australia; 2012 29/10/ 2012.

30 Wagner AK, Soumerai SB, Zhang F, et al. Segmented regression analysis of interrupted time series studies in medication use research. J Clin Pharm Ther 2002;27:299-309.

31 Bernal JL, Cummins S, Gasparrini A. Interrupted time series regression for the evaluation of public health interventions: a tutorial. Int J Epidemiol 2017;46:348-55.

32 Colchero MA, Popkin BM, Rivera JA, et al. Beverage purchases from stores in Mexico under the excise tax on sugar sweetened beverages: observational study. BMJ 2016;352:h6704.

33 Huang R, Kiesel K. Does limited access at school result in compensation at home? the effect of soft drink bans in schools on purchase patterns outside of schools. Eur Rev Agric Econ 2012;39:797-820.

34 Lichtman-Sadot S. Does banning carbonated beverages in schools decrease student consumption? J Public Econ 2016;140:30-50.

35 Penfold RB, Zhang F. Use of interrupted time series analysis in evaluating health care quality improvements. Acad Pediatr 2013;13:S38-44.

36 Euromonitor International. Soft drinks quarterly briefing Q4. Euromoniter International, 2017.

37 Euromonitor International. Voice of the industry: soft drink. Euromonitor International, 2018.

38 Duffey K, Poti J. Modeling the effect of replacing sugar-sweetened beverage consumption with water on energy intake, HBI score, and obesity prevalence. Nutrients 2016;8:395.

39 von Philipsborn P, Stratil JM, Burns J, et al. Environmenta interventions to reduce the consumption of sugar-sweetened beverages and their effects on health. Cochrane Database Syst Rev $2016 ; 135$ 